\title{
Subcellular localization of glyoxylate cycle key enzymes involved in oxalate biosynthesis of wood- destroying basidiomycete Fomitopsis palustris grown on glucose
}

\author{
Shunsuke Sakai, ${ }^{1} \dagger$ Tatsunori Nishide, ${ }^{1} \ddagger$ Erman Munir, ${ }^{2}$ Kei'ichi Baba, ${ }^{1}$ \\ Hiroshi Inui, ${ }^{3}$ Yoshihisa Nakano, ${ }^{3}$ Takefumi Hattori ${ }^{1}$ and Mikio Shimada ${ }^{1} \S$ \\ ${ }^{1}$ Research Institute for Sustainable Humanosphere, Kyoto University, Uji, Kyoto 611-0011, \\ Japan \\ ${ }^{2}$ University of North Sumatra, Jl. Bioteknologi No. 1 Kampus USU, Medan 20513, Indonesia \\ ${ }^{3}$ Department of Applied Biological Chemistry, University of Osaka Prefecture, Sakai, Osaka \\ 599-8231, Japan
}

Correspondence

Takefumi Hattori

thattori@rish.kyoto-u.ac.jp

Received 21 November 2005

Revised 27 January 2006

Accepted 14 February 2006

\section{INTRODUCTION}

The glyoxylate (GLOX) cycle, which was first discovered by Kornberg \& Krebs in 1957, involves two key enzymes, isocitrate lyase (ICL; EC 4.1.3.1) and malate synthase (MS; EC 2.3.3.9). ICL, threo- $\mathrm{D}_{\mathrm{S}}$-isocitrate-glyoxylate-lyase, catalyses the reversible conversion of isocitrate to succinate and glyoxylate (Campbell et al., 1953). The glyoxylate intermediate is further condensed with acetyl-CoA, yielding malate by catalysis of MS (Wong \& Aji, 1956). Thus,

†Present address: Department of Microbiology, Graduate School of Medicine, Kyoto University, Kyoto 606-8501, Japan.

‡Present address: Nisshin Foods Inc., Tokyo, Japan.

§Present address: Environmental and Biotechnological Frontier Engineering, Fukui University of Technology, Fukui, Japan.

Abbreviations: ACS, acetyl-CoA synthase; DAB, diaminobenzidine; FPICL1, Fomitopsis palustris isocitrate lyase 1; GLOX, glyoxylate; $\mathrm{IDH}$, isocitrate dehydrogenase; $\mathrm{MDH}$, malate dehydrogenase; MS, malate synthase; NTA, nitrilotriacetate; $\mathrm{ODH}, 2$ 2-oxoglutarate dehydrogenase; OXA, oxaloacetate acetylhydrolase; PNS, post-nuclear supernatant; PTS1, peroxisomal target signal 1; $\mathrm{SDH}$, succinate dehydrogenase. for maintaining the TCA cycle, the GLOX cycle enables a net synthesis of $\mathrm{C}_{4}$ carboxylic acids from a carbon source of $\mathrm{C}_{2}$ compounds (Kornberg \& Madsen, 1957; Kornberg \& Krebs, 1957; Kornberg, 1966), such as acetate, ethanol, and fatty-acid-derived acetyl-CoA.

In general, micro-organisms induce ICL as an adaptive enzyme for gluconeogenesis only when they are grown on $\mathrm{C}_{2}$ compounds (Vanni et al., 1990). However, when glucose is present together with these non-fermentable compounds, expression of an ICL-encoding gene is repressed, or, in some cases, the ICL protein is further inactivated, which is called catabolite repression or inactivation (Herrero et al., 1985; López-Boado et al., 1988; Fernández et al., 1992; De Lucas et al., 1994; Ordiz et al., 1996; Amor et al., 2000; Schüller, 2003; López et al., 2004).

In contrast to the above biochemical features of ICLs, both ICL and MS occur as constitutive enzymes in a wide variety of glucose-grown wood-destroying basidiomycetes, including Fomitopsis palustris (Munir et al., 2001a). Furthermore, $F$. palustris accumulates oxalate in the culture fluid, 
producing a yield of $80 \%$ based on the amount of glucose consumed during vegetative growth (Munir et al., 2001b). The acid formed plays a crucial role in the wood-decaying process (Dutton \& Evans, 1996; Shimada et al., 1997). Biochemical analysis of the unique oxalate fermentation of $F$. palustris has led to the conclusion that the fungus acquires biochemical energy for growth by oxidizing glucose to oxalate. In such an acid fermentation process, ICL, shared by the GLOX and TCA cycles, plays a major role, whereas neither isocitrate dehydrogenase (IDH) nor 2-oxoglutarate dehydrogenase $(\mathrm{ODH})$ plays a significant role (Munir et al., 2001b). Thus, the constitutive key enzyme ICL replenishes the intermediates glyoxylate and succinate to the GLOX and TCA cycles, respectively (Munir et al., 2001b). The role of $F$. palustris ICL is contrasted with the hither-to-known function of ICL required for gluconeogenesis in other micro-organisms.

In view of this unique carbon metabolism in F. palustris, one question arises: in which organelle in the cell of $F$. palustris are the GLOX enzymes cytochemically compartmentalized? Microbial ICL is generally found in microbodies called peroxisomes (Osumi et al., 1978; Valenciano et al., 1996, 1998; Titorenko et al., 1998; Maeting et al., 1999) or glyoxysomes (Kionka \& Kunau, 1985), with a few exceptions (Taylor et al., 1996; Chaves et al., 1997; Ono et al., 2003). In the case of basidiomycetes, the ICL of the litterdecomposing Coprinus lagopus grown on acetate has been found to occur in peroxisomes by subcellular fractionation analysis (O'sullivan \& Casselton, 1973). However, those authors detected ICL activity from a lighter buoyant density fraction than the mitochondrial fraction, which contradicts results reported for several other micro-organisms. The ICL of Coprinus cinereus acu-7 has been proposed to be peroxisomal based on the presence of the peroxisome target signal (PTS1) (Subramani, 1993) at the C terminus (Chaure et al., 1997), without direct experimental evidence. Furthermore, localization of the induced ICLs has been investigated for micro-organisms grown on $\mathrm{C}_{2}$ compounds, but, to the best of our knowledge, the ICL localization for glucosegrown micro-organisms has not been reported.

Therefore, we were motivated to investigate the intracellular localization of the GLOX cycle enzymes, and other enzymes involved in oxalate fermentation, in glucose-grown $F$. palustris. Previously, we purified and characterized ICL from F. palustris (Munir et al., 2002), which is termed FPICL1 in this study. We report here the characterization of FPICL1 cDNA encoding FPICL1, and peroxisomal localization of FPICL1 based on subcellular fractionation and immunocytochemical experiments using anti-FPICL1 antibody. The localization of MS, acetyl-CoA synthase (ACS; EC 6.2.1.1) and oxaloacetate acetylhydrolase (OXA; EC 3.7.1.1) was also determined. The results are discussed in relation to possible transportation of metabolites between subcellular sites, and also in relation to the constitutive metabolic coordination of the TCA and GLOX cycles with the oxalate biosynthesis.

\section{METHODS}

Fungal strain and culture conditions. The wood-destroying basidiomycete F. palustris (Berkeley et Curtis) Murill (formerly named Tyromyces palustris) strain TYP-6137, a Japanese industrial standard fungus for wood-preservative efficacy tests, was used in this study. This fungus was maintained at $32{ }^{\circ} \mathrm{C}$ on a potato glucose agar (PDA) culture. The fungal inocula were prepared from a colony fully grown on the agar, and removed with a cork borer $(6 \mathrm{~mm}$ diameter). Ten plugs of mycelia were used as inocula, and cultured at $32{ }^{\circ} \mathrm{C}$ for 4 days in the dark in a 1 litre Erlenmeyer flask, with $200 \mathrm{ml} \mathrm{2} \%(\mathrm{w} / \mathrm{v})$ glucose medium $(\mathrm{pH} 5 \cdot 5)$ containing $0 \cdot 8 \%(\mathrm{w} / \mathrm{v})$ peptone, $0.05 \%(\mathrm{w} / \mathrm{v}) \mathrm{KH}_{2} \mathrm{PO}_{4}, 0.05 \%(\mathrm{w} / \mathrm{v}) \mathrm{K}_{2} \mathrm{HPO}_{4}, 0.03 \%(\mathrm{w} / \mathrm{v})$ $\mathrm{MgSO}_{4} \cdot 7 \mathrm{H}_{2} \mathrm{O}$ and 5 p.p.m. thiamine/HCl (Munir et al., 2001a). Fresh mycelia were processed for the experiments described below.

Amino acid sequencing. Purified ICL protein (approx. $80 \mu \mathrm{g}$; Munir et al., 2002) was digested with lysylendopeptidase, and the resulting peptides were separated by HPLC on a reverse-phase C18 column. N-terminal amino acid sequences were determined by use of an ABI Precise 491 automated protein sequencer (Applied Biosystems). Protein concentrations were determined by the method of Bradford (1976), using BSA as a standard.

Isolation of cDNA encoding FPICL1. Total RNA was extracted from the mycelia of glucose-grown F. palustris by use of a QuickPrep Total RNA Extraction kit (Amersham Biosciences), according to the manufacturer's instructions. PolyA ${ }^{+}$RNA was isolated from the total RNA using Oligotex-dT30<Super $>$ (Takara Bio), and cDNA was synthesized with a Timesaver cDNA synthesis kit (Amersham Biosciences), followed by size fractionation into pools containing more than $0 \cdot 5 \mathrm{~kb}$. The cDNA pool was cloned into a lambda ZAP II vector containing the whole phagemid pBluescript SK sequence (Stratagene), and packaged into $\lambda$ phage extract (Gigapack III packaging extract kit; Stratagene). The cDNA library was constructed with $3 \cdot 5 \times 10^{5}$ p.f.u. $\mu \mathrm{g}^{-1}$.

In order to prepare probe for the screening of FPICL1, PCR was performed with the CDNA, prepared as described above, as a template, and a pair of primers, (P1, 5'-GGTCACATGGCTGGTAAGGT-3'; and P2, 5'-GACCGGCGAGAGTGATGAAC-3'), which were designed from the sequences within the Aspergillus nidulans ICL gene ( $a c u D$; GenBank accession no. X62696). We screened cDNA encoding the putative protein, including the internal amino acid sequence of FPICL1. The amplified fragment was subsequently used as an $\left[\alpha^{32} \mathrm{P}\right] \mathrm{dATP}-$ labelled probe for cDNA library screening by standard plaque hybridization procedures (Sambrook et al., 1989). Because the obtained cDNA fragment lacked the 5 ' region, we performed PCR using a cDNA library that had been newly constructed by Takara Bio as a template, and a pair of primers (P3, 5'-GAAAGAAAAAAAATATACCCCAGC-3'; and P4, 5'-ACCTTGCCCGCCATATGCCCGCACTTCTT- $3^{\prime}$ ), in order to determined the sequence of the $5^{\prime}$ end of the cDNA. DNA sequencing was performed by Big Dye terminator v2.0 Ready Reaction Cycle Sequencing Kit (Applied Biosystems) and an ABI PRISM 377 DNA sequencer (Applied Biosystems).

Subcellular fractionation. Cell organelles were obtained from the protoplast homogenate by differential centrifugation. Approximately $100 \mathrm{~g}$ (wet wt) of mycelia were harvested by filtration through cheesecloth, and washed well with distilled water. Mycelial mats were suspended in a lysing buffer $[50 \mathrm{mM}$ maleate, $\mathrm{pH} 6 \cdot 0$, containing $0.6 \mathrm{M}$ mannitol, $1 \mathrm{mM}$ EDTA and $5 \%(\mathrm{w} / \mathrm{v})$ Lysing Enzyme (Sigma-Aldrich)], and gently shaken at $28^{\circ} \mathrm{C}$. After $2-3 \mathrm{~h}$, protoplast formation was complete, and the lysate was chilled to $4{ }^{\circ} \mathrm{C}$. The protoplasts were collected at $4{ }^{\circ} \mathrm{C}$ by a low-speed centrifugation, resuspended in a protoplast buffer $(50 \mathrm{mM}$ Tris/ $\mathrm{HCl}, \mathrm{pH} 7 \cdot 5)$ containing $1 \mathrm{M}$ sorbitol, $1 \mathrm{mM}$ EDTA and $1 \mathrm{mM}$ PMSF, and homogenized in a 
Potter-Elvehjem homogenizer with a loosely fitting Teflon pestle. The homogenate was centrifuged at $1500 \mathrm{~g}$ for $10 \mathrm{~min}$ to remove cell debris and nuclei. The post-nuclear supernatant (PNS) was filtered through Miracloth (Calbiochem), and then centrifuged at $20000 \mathrm{~g}$ for $20 \mathrm{~min}$, to yield pellet $(20 \mathrm{KgP})$ and supernatant $(20 \mathrm{KgS})$ fractions. The $20 \mathrm{KgP}$ fraction, consisting mainly of mitochondria and peroxisomes, was resuspended in a suspension buffer $(50 \mathrm{mM}$ Tris/ $\mathrm{HCl}, \mathrm{pH} 7 \cdot 5$ ) containing $0.5 \mathrm{M}$ sucrose, $1 \mathrm{mM}$ EDTA and $1 \mathrm{mM}$ PMSF, and layered onto a discontinuous sucrose densitygradient [ $1 \mathrm{ml} 60 \%(\mathrm{w} / \mathrm{v})$ sucrose, $2 \mathrm{ml}$ each of $50,46,43$, and $41 \%$ sucrose, and $1 \mathrm{ml} 35 \%$ sucrose, in $10 \mathrm{mM}$ Tris/ $\mathrm{HCl}(\mathrm{pH} \mathrm{7 \cdot 5)].} \mathrm{The}$ gradient solution was centrifuged at $100000 \mathrm{~g}$ for $5 \mathrm{~h}$ at $4{ }^{\circ} \mathrm{C}$ in a Beckman SW40 Ti swinging-bucket rotor. Fractions of $0.75 \mathrm{ml}$ were collected from the bottom of the tube, and analysed for various enzyme activities. The sucrose concentration of each fraction was determined refractometrically at $25^{\circ} \mathrm{C}$. Each operation was done in triplicate.

Enzyme assays. All enzyme assays were performed spectrophotometrically at $30^{\circ} \mathrm{C}$ by use of a Shimadzu UV-1650P spectrophotometer. ICL and MS activities of a glyoxylate cycle marker were determined by the method of Dixon \& Kornberg (1959). ICL activity was assayed by measurement of the increase in absorbance at $324 \mathrm{~nm}$ due to the formation of the phenylhydrazone derivative of glyoxylate produced from isocitrate. MS activity was determined on the basis of the consumption of acetyl-CoA, with a decrease in absorbance at $340 \mathrm{~nm}$. Catalase (EC 1.11.1.6) activity, as a peroxisomal marker, was determined by measuring the decomposition of $\mathrm{H}_{2} \mathrm{O}_{2}$ by the method of Aebi (1983). Succinate dehydrogenase (SDH; EC 1.3.5.1) activity as a mitochondrial marker was measured on the basis of a modified method of Moore \& Ewaze (1976). Malate dehydrogenase (MDH; EC 1.1.1.37) activity was assayed as described by Labrou et al. (1997). ACS activity was assayed according to the method of Heather \& Fairhurst (1998). OXA activity was determined by measurement of the decrease in absorbance at $255 \mathrm{~nm}$ due to the hydrolysis of oxaloacetate (Lenz et al., 1976). One unit of enzyme activity is defined as the amount of enzyme that catalyses the formation or decomposition of $1 \mu \mathrm{mol}$ product or substrate, respectively, per minute, under the conditions described.

Generation of anti-FPICL antibody. To obtain the pure protein [terminated with an SKL tripeptide representing a peroxisome targeting signal 1 (PTS1)] for generating an anti-FPICL1 antibody, the pET-32 Ek/LIC expression system (Novagen) was used. A DNA fragment encoding C-terminal 336 aa (out of a total of 539 aa) was amplified by PCR with the primer pairs designed from the FPICL1 sequences, and subcloned into the expression vector. The truncated protein is expressed as the fusion protein with thioredoxin, H-tag and S-tag at the $\mathrm{N}$ terminus. Escherichia coli strain Origami B (DE3) was cultured in Luria-Bertani medium supplemented with $100 \mu \mathrm{g}$ ampicillin $\mathrm{ml}^{-1}$ at $30^{\circ} \mathrm{C}$, and protein expression was induced by IPTG added at a final concentration of $0.1 \mathrm{mM}$. Cells were harvested by centrifugation, and suspended in $20 \mathrm{mM} \mathrm{Tris} / \mathrm{HCl}$ ( $\mathrm{pH} 7 \cdot 0$ ) containing $0.3 \mathrm{M} \mathrm{NaCl}$ and $20 \mathrm{mM}$ imidazole. After sonication, cell lysates were subjected to affinity chromatography using a $\mathrm{Ni}^{+}$-nitrilotriacetate (NTA) column, and the purified fusion protein was incubated with enterokinase to remove the N-terminal tags. The enterokinase coexisting in the sample was captured with EKapture Agarose (Novagen). The recombinant protein without a tag was rescued from the fraction passed through the $\mathrm{Ni}^{+}$-NTA column. SDS-PAGE analysis (Laemmli, 1970) revealed a protein band with an apparent molecular mass of $39 \mathrm{kDa}$, which corresponded to the deduced size of the FPICL1 truncation (not shown).

The homogeneous protein $(1 \cdot 2 \mathrm{mg})$, emulsified with the same volume of Freund's complete adjuvant ( $2 \mathrm{ml}$ total volume), was used to immunize rabbits. This was followed by two additional booster injections. One week after the second injection, a blood sample was collected to measure the titre of the antibody by ELISA. After the last injection, the rabbit was killed under anaesthesia. Blood was centrifuged at $3000 \mathrm{~g}$ for $10 \mathrm{~min}$, and the antiserum fraction was pooled, and stored at $-80^{\circ} \mathrm{C}$ until use.

Western blotting. Proteins were separated on an SDS-PAGE gel containing $15-25 \%$ polyacrylamide, and electrotransferred to PVDF membranes (Immobilon-P; Millipore). The membrane was blocked in $0.5 \%(\mathrm{w} / \mathrm{v})$ skim milk in PBS-T $(0.05 \%$ Tween-20 in PBS), and then incubated with rabbit polyclonal antibody raised against FPICL1 ( $1: 3000$ dilution in PBS-T) or control rabbit serum $(1: 2000$ dilution in PBS-T). After washing in PBS-T, the membrane was incubated with horseradish-peroxidase-conjugated donkey anti-rabbit IgG secondary antibody (1:5000 dilution in PBS-T). The immunoreactive proteins were detected by chemiluminescence with the ECL detection system (Amersham Biosciences), according to the manufacturer's instructions. Preparation of cell-free extracts from F. palustris, and purification of the native enzyme, were performed by the methods of Munir et al. (2002).

Electron microscopy and immunocytochemistry. F. palustris mycelia grown on glucose medium were pre-fixed in $2.5 \%(\mathrm{v} / \mathrm{v})$ glutaraldehyde and $1.5 \%(\mathrm{w} / \mathrm{v})$ paraformaldehyde in $20 \mathrm{mM}$ PIPES $(\mathrm{pH} 7 \cdot 2)$ for $3 \mathrm{~h}$ at $4{ }^{\circ} \mathrm{C}$. Pre-fixed samples prepared were washed three times with the buffer, and fixed overnight at $4{ }^{\circ} \mathrm{C}$ in $1 \%(\mathrm{w} / \mathrm{v})$ $\mathrm{OsO}_{4}$ in $20 \mathrm{mM}$ PIPES ( $\mathrm{pH} 7 \cdot 2$ ). After dehydration in a graded ethanol series at room temperature, the samples were embedded in Spurr's resin (Spurr, 1969), and serially sectioned on a Reichert ultramicrotome (Ultracut E; Reichert-Jung). Ultrathin sections mounted on nickel grids were stained with uranyl acetate at room temperature, followed by lead citrate staining. For cytochemical staining of catalase, a glutaraldehyde/paraformaldehyde-fixed sample was incubated for $3 \mathrm{~h}$ at $4{ }^{\circ} \mathrm{C}$ with diaminobenzidine (DAB; $1 \mathrm{mg}$ $\mathrm{ml}^{-1}$ ) in $100 \mathrm{mM}$ Tris/ $\mathrm{HCl}(\mathrm{pH} \mathrm{10} \cdot 5)$, containing $0 \cdot 1 \% \mathrm{H}_{2} \mathrm{O}_{2}$, before $\mathrm{OsO}_{4}$-fixation. In control experiments with a catalase inhibitor, 3-amino-1,2,4-triazole, a pre-fixed sample was incubated for 30 min with this chemical, and then transferred to DAB solution.

For immunoelectron microscopy, mycelia were fixed overnight at $4{ }^{\circ} \mathrm{C}$ in $0.2 \%$ glutaraldehyde and $4 \%$ paraformaldehyde in $20 \mathrm{mM}$ PIPES (pH 7.2), containing $0.5 \mathrm{mM} \mathrm{CaCl}_{2}$. Samples were washed three times with the buffer, dehydrated in a graded ethanol series, and embedded in LR-White resin (London Resin). Ultrathin sections were cut with an ultramicrotome. The sections were blocked in $0 \cdot 1 \%$ BSA in PBS for $30 \mathrm{~min}$ at room temperature, and incubated for $1 \mathrm{~h}$ with anti-FPICL1 antiserum $(1: 30$ dilution in PBS) or non-immune rabbit serum ( $1: 40$ dilution in PBS). After washing in PBS, the sections were incubated for $1 \mathrm{~h}$ with goat anti-rabbit IgG antibody conjugated with $15 \mathrm{~nm}$ gold particles $(1: 20$ dilution in PBS-T). The sections were washed in distilled water, and then stained with uranyl acetate. After staining, all sections were examined with a JOEL 1200 EX transmission electron microscope at $100 \mathrm{kV}$.

\section{RESULTS AND DISCUSSION}

\section{Characterization of FPICL1}

We determined the sequence of the cDNA encoding FPICL1 (AB079254). The deduced amino acid sequence contained an ORF that corresponded to 539 residues (Fig. 1). All of the 10 polypeptides obtained from FPICL1 by digestion with lysylendopeptidase were found in this deduced amino acid sequence. The hexapeptide KKCGHM, highly conserved as an ICL signature in the sequences of most ICLs reported to 
F. palustris

$P$. chrysosporium

C. cinereus

A. nidulans

S. cerevisiae

F. palustris

P. chrysosporium

C. cinereus

A. nidulans

s. cerevisiae

F. palustris

$P$. chrysosporium

C. cinereus

A. nidulans

S. cerevisiae

F. palustris

P. chrysosporium

C. cinereus

A. nidulans

S. cerevisiae

F. palustris

$P$. chrysosporium

C. cinereus

A. nidulans

s. cerevisiae

F. palustris

$P$. chrysosporium

C. cinereus

A. nidulans

s. cerevisiae

F. palustris

P. chrysosporium

C. cinereus

A. nidulans

S. cerevisiae

F. palustris

P. chrysosporium

C. cinereus

A. nidulans

S. cerevisiae

F. palustris

$P$. chrysosporium

C. cinereus

A. nidulans

S. cerevisiae

F. palustris

$P$. chrysosporium

C. cinereus

A. nidulans

S. cerevisiae

\begin{abstract}
- - - - - - - -MSNERAAFQAEVARVEQWWKDPRFNRVKRPYTAAQVVS $\overline{\text { KRGTLPISYPS }}$
- - - - - - - - MSYSERAI LKAEAAQVEQWWKDYRFRKVKRPYTAEQVVSKRGT I P IQYPS

- - - - - - - - - - - - - - - -MSYIEEEDQRYWDEVAVKNWWKDSRWRYTKRP FTAEQIVAKRGNLK IEYPS

MPIPVGNTKNDFAALQAKLDADAAEIEKWWSDSRWSKTKRNYSARDIAVRRGTFPPIEYP

$$
\text { : : : :**..*: }::^{*}::^{*}::::^{\star *} .:
$$
\end{abstract}

DVLAKKLWASLTQHYKNGTPSHTYGALDPVQVTQMATYLETVYVSGWQSSSTASSSNEPG 109 NIOAKKLYALLDEKFKRREP SHTYGALDPVOLTQMAKYLETVYVSGWQSSSTASSTNEPG 110 DVQGKKLWKLLSEHAKNGTP SHTYGALDPVQVTKMAKYLETVYVSGWQSSSTASS SNEPG 109 NVQAKKLWGILERNEN-KEASFTYGCLDPTMVTQMAKYLDTVYVSGWQSSSTASSTDEPS 110 SVMARKLFKVLEKHHNEGTVSKTFGALDPVQISQMAKYLDTIYISGWQCSSTASTSNEPG 120

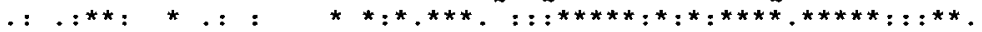

PDLADYPSNTVPNKVEHLFMAQLFHDRKQAEARSNLSEAELAQTP - -VIDYLRPI IADAD 167 PDLADYPSNTVPNKVEHLFMAOLFHDRKOREARSRLSDAELAKTP - -AIDYLRPI IADAD 168 PDLADYPSNTVPNKVEHLFMAQLFHDRKQREARSRMSDAELANTP - -VIDYLRPIVADAD 167 PDLADYPMNTVPNKVNHLWMAQLFHDRKQREERMTTPKDQRHKVT - -NVDYLRPI IADAD 168 PDLADYPMDTVPNKVEHLFKAQLFHDRKQLEARSKAKSQEELDEMGAP IDYLTPIVADAD 180

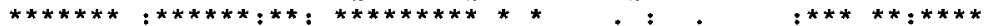

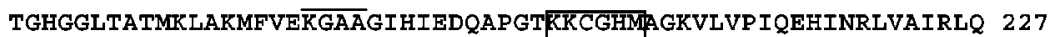
TGHGGLTATMKLAKMFVEKGAAGIHIEDQAPGTKKCGHMAGKVLVPIQEHINRLVAIRLQ 228 TGHGGLTAVMKLTKMFVEKGAAGIHIEDQAPGTKKCGHMAGKVLVPIQEHINRLVAIRLQ 227 TGHGGLTAVMKLTKLFVERGAAGI HIEDQAPGTKKCGHMAGKVLVPISEHINRLVAIRAQ 228 AGHGGLTAVFKLTKMFIERGAAGI HMEDQTSTNKKCGHMAARCVIPVQEHVNRLVTIR - 238

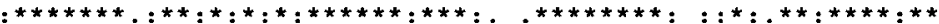

FDIMGVNNLVIARTDSEAATLITTNVDERDHAFILGSTNPDLRPLNTLLNEAERAGKTGĀ 287 FDVMGVDNLVIARTDSEAATLITSNIDERDHPFILGSTNPNQRPLVVVLNEAEAQGKVGA 288 YDIMGVENLVVARTDSEAATLITSNIDDRDHPFIQGSTNPSLPPLNNVMVEAEAOGKTGD 287 ADIMGTDLLAIARTDSEAATLITSTIDHRDHPFIIGSTNPDIQPLNDLMVMAEQAGKNGA 288 - -MMHSDLIVVARTDSEAATLISSTIDTRDHYFIVGATNPNIEPFAEVLNDAIMSG- -AS 294

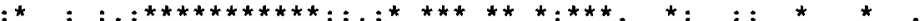

$\overline{A L E A V} E E Q W L A A A K L Q L F P E V L A N A L K A Q T G A N Q V \overline{K L E Q F H R R V A-~-H L S Y P D A V A V A K K ~} 345$ ELEAIEEQWINAAGLALFGTVLANALKAQG-ANPTALERFHARVA--HVSWPRAVEIAKH 345 QLQAIEDGWIKAANLQLFPQALAQALANEG-ASRSTVEKLVARVS - RLSWSOAVAVAOK 344 ELQAIEDEWLAKAGLKLFNDAVVDAINNSPLPNKKAAIEKYLTQS - -KGKSNLEARAIAK 346 GLADIEQKWCRDAGLKLFHEAVIDEIERSALSNKQELIKKFTSKVGPLTETSHREAKKLA 354

* * * * * * * : : :

EFGLRSAPFWDWDAPRTREGFYRYQGGTQCAVNRAIAFAPYADLLWMETKKPIYAQA $\overline{\overline{K E F}} 405$ EFGLRQVPHWDWDAPRTREGFYRYRGGTKCAINRA IAYAPYADALWMETEKPILAQAREF 405 EFGLKOVPYWNWDAPRTREGYYRYOGGTECAIHRANAFAPYADLLWMETKKPILAOAKEF 404 EIAG-TDIYFDWEAPRTREGYYRYQGGTQCAINRAVAYAPFADLIWMESKLPDYKQAKEF 405 KEILGHEIFFDWELPRVREGLYRYRGGTQCSIMRARAFAPYADLVWMESNYPDFQQAKEF 414

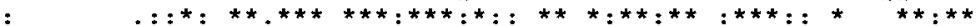

$\overline{A D G V H A V Y P D Q W L A Y N L S P S F N W E A A G L N E Q D M R A F V W D L G K L G F C W Q F I T L A G L H S N A Y ~} 465$ AEGVHAVYPEQWLAYNLSPSFNWEAAGLNTEDMKNYVWDLGKLGFVWQFITLGGLHSNAY 465 AAGVHAVHPGOWLAYNLSPSFNWKLLPOR-ODMOAYVWELGKLGFVWOFITLAGLHSNAY 463 ADGVHAVWPEQKLAYNLSPSFNWKKAMPR-DEQETYIKRLGALGYAWQFITLAGLHTTAL 464 AEGVKEKFPDQWLAYNLSPSFNWPKAMSV-DEQHTFIQRLGDLGYIWQFITLAGLHTNAL 473

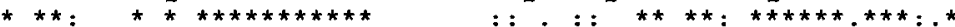

ISDLFAKAFATEGMKAYVELVQRREREIGCDVLTHQKWSGADYMDNLMKTVTGGVSSTAA 525 ISDLFAKNFAKEGMKAYVELIQRREREIGCDVLTHQKWSGADYMDNLMKTVTGGVSSTAA 525 I SDLFAQNFAKTGMKAYVELVQSREREIGCDVLTHQKWSGADYADSLIKTVTGGVSSTAA 523 ISDTFAKAYAKQGMRAYGELVOEPEMANGVDVVTHQKWSGANYVDNMLKMITGGVSSTAA 524 AVHNF SRDFAKDGMKAYAQNVQQREMDDGVDVLKHQKWS-GEYIDGLLKLAQGGVSATAA 532

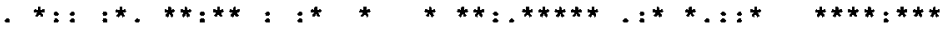

MGKGVTESQFSSKL- - 539

MGKGVTENQFHSKL-- - 539

MGAGVTESOFTSKL - - 537

MGKGVTEDOFKS - - - - 536

MGTGVTEDQFKENGVKR 549

$* * * * * . * *$.

Fig. 1. Alignment of the deduced amino acid sequences of ICLs from various micro-organisms. The sequence alignment was performed using the CLUSTAL W program (Thompson et al., 1994). Identical amino acid residues are marked with asterisks. Conservative residue substitutions are indicated by two dots, and semi-conservative substitutions by one dot. Internal amino acid sequences derived from native FPICL1 are marked with lines over the top. The conserved hexapeptide sequence used as an ICL signature, and the C-terminal tripeptide SKL, representing PTS1, are boxed. The sequences have been deduced from the following nucleotide sequences: F. palustris (FPICL1; DDBJ, EMBL, GenBank accession no. AB079254), P. chrysosporium (ICL; JGI assigned name pc.102.5.1), C. cinereus (acu7, EMBL accession no. X98860), A. nidulans (acuD; EMBL accession no. X62696), and S. cerevisiae (ICL1; EMBL accession no. X65554). 
date, was found in the sequence at aa 201-206. The deduced polypeptide had a predicted molecular mass of $59735 \mathrm{Da}$, which is similar to the estimated molecular mass for the purified FPICL1 (Munir et al., 2002). By analogy with acu-D, the ICLs of $A$. nidulans (Gainey et al., 1992), D111,
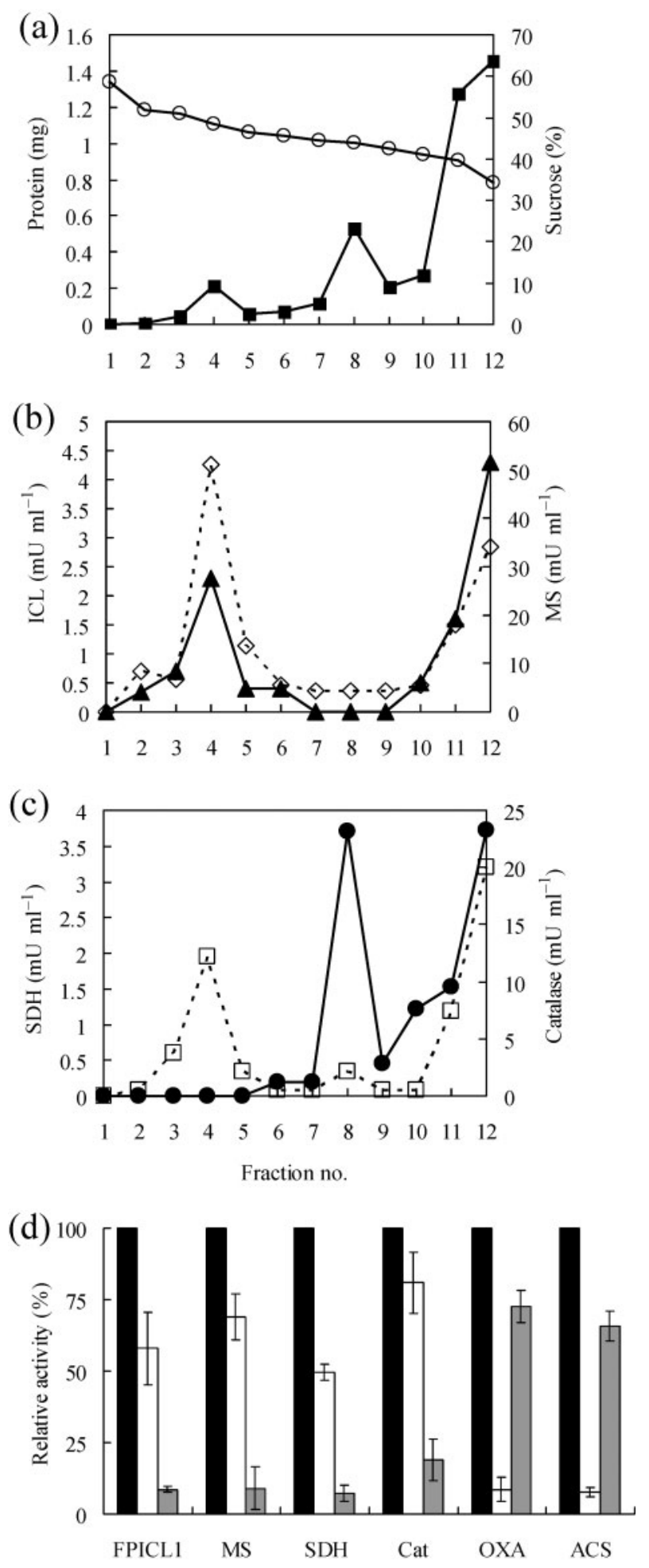

Distribution of enzymes after differential centrifugation
D165, D167 and E194 are suggested to be a cluster for the $\mathrm{Mg}^{2+}$-binding site. The predicted amino acid sequence was compared with those of the ICLs of Phanerochaete chrysosporium, C. cinereus (Chaure et al., 1997), A. nidulans (Gainey et al., 1992) and Saccharomyces cerevisiae (Schöler \& Schüller, 1993), which revealed 83, 79, 63 and $54 \%$ identity, respectively (Fig. 1). Interestingly, FPICL1 was found to contain the motif KRGT at positions $39-42$. This is a putative cAMP-dependent protein kinase phosphorylation site for the $\mathrm{T}$ residue. A similar site has been found in C. cinereus acu7 (Chaure et al., 1997), and ICL1 sequences of S. cerevisiae (Fernández et al., 1992) and Candida tropicalis (Atomi et al., 1990). In particular, S. cerevisiae ICL1 has been proposed to be phosphorylated at T53, followed by inactivation in the presence of glucose (López-Boado et al., 1988; Ordiz et al., 1996). However, the role of the motif KRGT in FPICL1 remains to be assessed. The C-terminal amino acids SKL, representing PTS1 (Subramani, 1993), suggest a peroxisomal localization of FPICL1 in F. palustris.

\section{The localization of catalase in peroxisomes in F. palustris}

We found that catalase was associated with a type of organelle that was thought to be a peroxisome. The detection of separate activities of SDH and catalase by subcellular fractionation showed that catalase was not localized in the mitochondria (Fig. 2a, c). Furthermore, greater than $80 \%$ of catalase activity was recovered from the pellet fraction $(20 \mathrm{KgP})$ containing mitochondria and peroxisomes, whereas $20 \%$ was from the supernatant fraction $(20 \mathrm{KgS})$ (Fig. 2d). The result strongly supports the localization of catalase in microbodies, but not in the cytosol. Moreover, the type of microbody that was stained with $D A B$ was distinct from mitochondria, as shown in Fig. 3(a, b), but it was not stained with $\mathrm{DAB}$ in the presence of a catalase inhibitor (data not shown) (Dijken et al., 1975; Fahimi \& Baumgart, 1999). Furthermore, the fact that catalase has been commonly used as a peroxisomal marker enzyme supports the peroxisomal localization of catalase in F. palustris. The finding is in accordance with oleate-grown A. nidulans (Valenciano et al., 1996), but is different from glucosegrown $S$. cerevisiae, in which catalase is widely distributed in mitochondria, peroxisomes and cytosol (Petrova et al., 2002).

Fig. 2. Distribution of enzyme activities in fractions of a sucrose density-gradient centrifugation ( $a, b$ and $c$ ), and differential centrifugation up to $20000 \boldsymbol{g}$ (d). (a) Protein (ם),

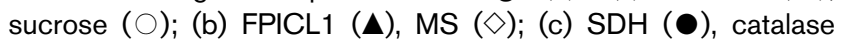
(Cat; $\square$ ); (d) relative enzyme activities in supernatant fraction (PNS) obtained from centrifugation at $3000 \mathrm{~g}$ (black bars). The activities in pellet $(20 \mathrm{KgP}$; white bars) and supernatant (20 KgS; grey bars) fractions obtained from centrifugation at $20000 \mathrm{~g}$ centrifugation. Data points represent means; SEM is given in (d), $n=3$. 

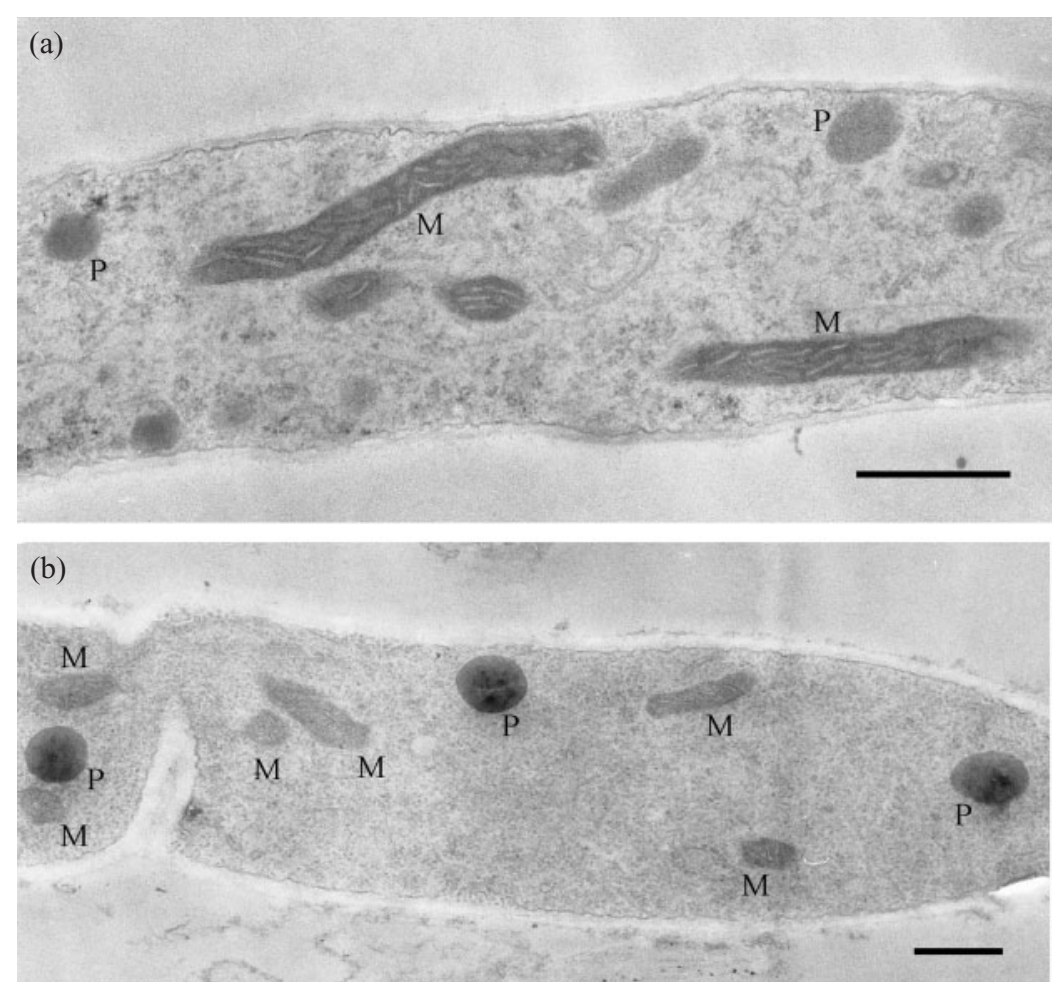

Fig. 3. Detection of catalase as a peroxisomal marker in mycelium of glucose-grown $F$. palustris. (a) Longitudinal section of a representative area of mycelium of $F$. palustris. (b) Cytochemical staining of catalase by $\mathrm{DAB} / \mathrm{H}_{2} \mathrm{O}_{2}$. $\mathrm{M}$, mitochondrion; $\mathrm{P}$, peroxisome. Bars, $1 \mu \mathrm{m}$.

\section{Subcellular localization of FPICL1}

FPICL1 and MS were found to be peroxisomal, because both FPICL1 and MS coexisted with catalase, but neither of them coexisted with SDH (Fig. 2a-c). Furthermore, FPICL1 and MS were not cytosolic. Greater than $60 \%$ of FPICL1, and $70 \%$ of MS, activities were recovered from the fraction containing microbody $(20 \mathrm{KgP})$, whereas only $10 \%$ each of the key enzymes was from the supernatant fraction containing cytosol (20KgS) (Fig. 2d).

The peroxisomal localization of FPICL1 was further confirmed by immunocytochemical analysis with rabbit antiserum containing anti-FPICL1 antibodies. We prepared the antiserum which specifically reacted with purified FPICL1. Only one protein band corresponding to the (a)

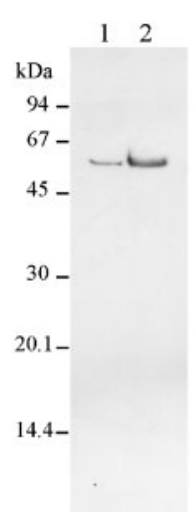

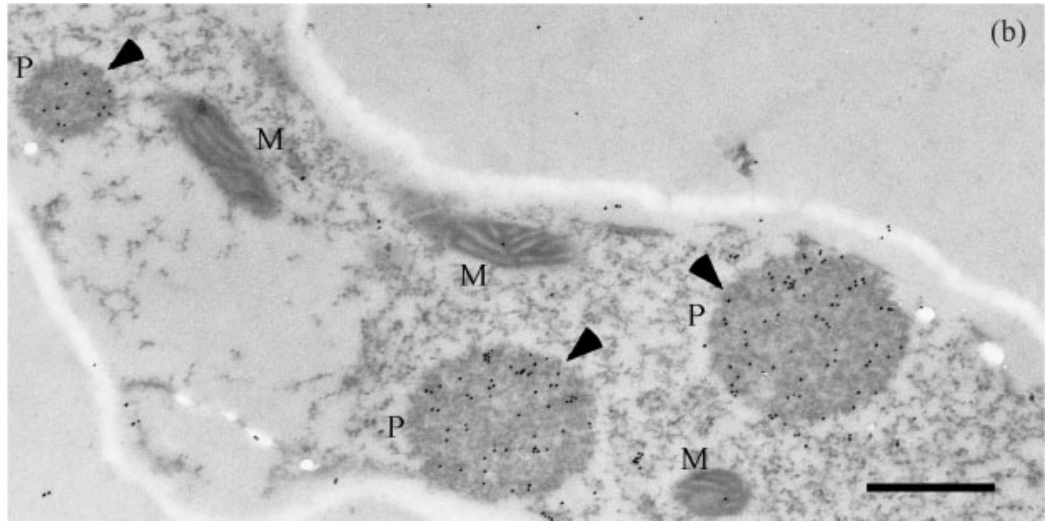

Fig. 4. Immunocytochemical localization of FPICL1 in the mycelium of glucose-grown F. palustris. (a) Detection of FPICL1 proteins by Western blot analysis. Proteins separated by SDS-PAGE ( $\mu \mathrm{g}$ in each lane) were reacted with rabbit anti-FPICL1 antibody (diluted 1:3000). Lane 1, cell-free extracts from F. palustris; lane 2, FPICL1 purified from the fungus. The positions of molecular mass markers are shown. (b) Immunoelectron microscopic detection of FPICL1. M, mitochondrion; $\mathrm{P}$, peroxisome. Bar, $1 \mu \mathrm{m}$. 
enzyme appeared on the gel loaded with cell-free extracts of F. palustris (Fig. 4a). A significant amount of immunogold labelling was located in the peroxisomes, but not in the cytosol or mitochondria (Fig. 4b). Alternatively, peroxisomal ICLs have been reported for Ashbya gossypii grown on $\mathrm{C}_{2}$ compounds (Maeting et al., 1999), C. tropicalis (Tanaka \& Ueda, 1993), Yarrowia lipolytica (Titorenko et al., 1998), A. nidulans (Valenciano et al., 1996), and a glyoxysome-like ICL for acetate or oleate-grown Neurospora crassa (Kionka \& Kunau, 1985). However, to the best of our knowledge, this investigation provides the first experimental evidence for peroxisomal localization of ICL in a glucose-grown basidiomycete.

\section{Subcellular localization of OXA and ACS}

Both OXA and ACS were shown to be cytosolic. Activities of $74 \%$ for OXA, and $66 \%$ for ACS, were recovered from the supernatant fraction $(20 \mathrm{KgS})$, whereas activities of less than
$10 \%$ for each enzyme were recovered from the pellet fraction (20KgP) (Fig. 2d). We found that there was no difference in MDH activity between the cytosolic and the pellet fractions (data not shown), which suggested that $\mathrm{MDH}$ isozymes were distributed in various organelles and cytosol in a cell of $F$. palustris. A similar finding has been reported for S. cerevisiae, in which $\mathrm{MDH}$ isozymes are distributed throughout the mitochondria, peroxisomes and cytosol (Steffan \& McAlister-Henn, 1992).

\section{Features of carbon metabolism of $\boldsymbol{F}$. palustris}

Although we previously proposed that ICL was shared by the TCA and GLOX cycles because of isocitrate metabolism (Munir et al., 2001b), we propose a revised model of carbon metabolism in relation to oxalate biosynthesis, as shown by the enzyme localizations in Fig. 5. The TCA and GLOX cycles, and acetate recycling, have been proposed to be involved constitutively in carbon metabolism for oxalate

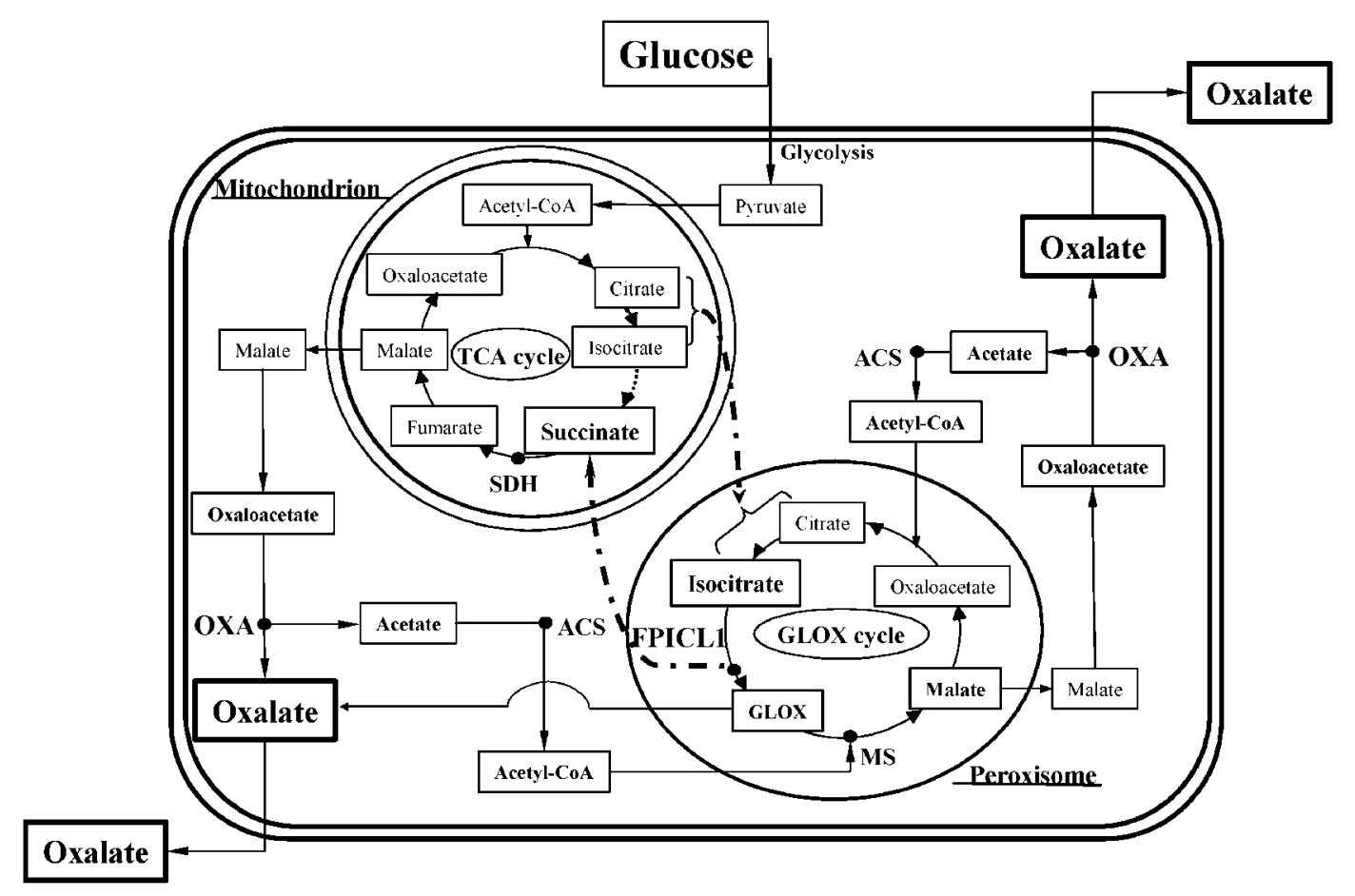

Fig. 5. Possible mechanisms for carbon metabolism in relation to oxalate biosynthesis in $F$. palustris, considering the localization of the TCA and GLOX cycles, and acetate recycling. Each metabolic step involved in the TCA and GLOX cycles, and acetate recycling, shown as normal arrows, has been proposed on the basis of enzyme activities that we detected from the mycelia of F. palustris (Munir et al., 2001b). However, we have not investigated the enzymes involved in the conversion of glucose to acetyl-CoA via pyruvate. Localization of the TCA and GLOX cycles, and acetate recycling, are proposed based on SDH, and FPICL1 and MS for the TCA and GLOX cycles, respectively, and ACS and OXA for acetate recycling. However, the localization of enzymes not shown in Fig. 5 remains to be elucidated. Transportation of malate to the cytosol has not been investigated for F. palustris, although the transportation is proposed to occur. Also, we have not shown experimental evidence for the transportation of succinate, citrate or isocitrate, and acetyl-CoA. Furthermore, the mechanism for oxalate excretion has not been elucidated. The dotted arrow indicates a small amount of conversion of isocitrate to succinate, since $\mathrm{ODH}$ activity has not been detected, and there is less activity of IDH than of FPICL1 (Munir et al., 2001b). The dot-and-dash arrow indicates speculative transportation between mitochondria and peroxisomes. 
fermentation of glucose-grown $F$. palustris, on the basis of enzyme activities detected from the mycelia catalysing each metabolic step shown in Fig. 5 (Munir et al., 2001b). The findings of peroxisomal FPICL1 and MS suggest a peroxisomal GLOX cycle, although the peroxisomal localization of $\mathrm{MDH}$, citrate synthase and aconitase needs to be demonstrated for conclusive confirmation of a peroxisomal GLOX cycle. On the other hand, the presence of mitochondrial SDH suggests a mitochondrial TCA cycle, although the mitochondrial localization of fumarase, $\mathrm{MDH}$, citrate synthase and aconitase remains to be investigated in order to confirm this. In this context, it is noteworthy that conversion of the $\mathrm{C}_{6}$ carboxylic acid to succinate through the TCA cycle is not thought to be significant, because a lower level of IDH activity than FPICL1 activity, and a lack of ODH activity, have been detected from the mycelia of F. palustris (Munir et al., 2001b). The presence of cytosolic ACS and OXA suggests that acetate recovery (Munir et al., 2001b) occurs in the cytosol, although the presence of cytosolic MDH needs to be demonstrated in order to confirm a cytosolic acetate recovery process. On the other hand, we have not investigated enzymes involved in conversion of glucose to acetyl-CoA via pyruvate.

Accordingly, we found that the FPICL1 in the GLOX cycle was not shared with the TCA cycle in mitochondria. It is proposed that the peroxisomal GLOX cycle, the mitochondrial TCA cycle, and cytosolic acetate recovery function in coordination with oxalate fermentation in F. palustris. The results allow us to postulate the following metabolite transportations for glucose-grown F. palustris, although we have not yet proved them. (1) Succinate may be transported from peroxisomes to mitochondria to replenish metabolite carbons for the TCA cycle. This hypothesis is supported by the separate localization of peroxisomal FPICL1 and mitochondrial SDH, together with the absence of $\mathrm{ODH}$ activity (Munir et al., 2001b). This speculated transportation of succinate is different from the inducible succinate transportation from the cytosol to mitochondria in $S$. cerevisiae grown on a non-fermentable carbon source (Flores et al., 2000). (2) Isocitrate or citrate transportation from mitochondria to peroxisomes may occur to solve the problem caused by the lesser catabolic activity for $\mathrm{C}_{6}$ carboxylic acid metabolism in the TCA cycle than in the GLOX cycle (Munir et al., 2001b). (3) Acetyl-CoA formed in the cytosol must be transported to mitochondria to be catabolized because of the large amount of acetate produced concomitantly with oxalate (Munir et al., 2001b). A similar process of acetyl-CoA formation and utilization, concomitant with oxalate production, has been proposed for $A$. niger (Ruijter et al., 1999). Alternatively, acetyl-CoA must be transported to peroxisomes as a substrate for MS and citrate synthase. However, the dual localization of citrate synthase and aconitase in mitochondria and peroxisomes remains to be elucidated, although dual localization of citrate synthase occurs in S. cerevisiae (Lee et al., 2000). These transportations are postulated to occur constitutively, because oxalate fermentation is indispensable for the growth of $F$. palustris
(Munir et al., 2001b). However, further research is needed to elucidate the mechanisms of transportation of the organic acid metabolites within a cell of $F$. palustris.

In conclusion, FPICL1 and MS are key enzymes of the GLOX cycle, and occur constitutively in peroxisomes in $F$. palustris grown on glucose. An acetate-recovery system operates in the cytosol, and thus organic acid metabolites involved in oxalate biosynthesis are finally oxidized to oxalate.

\section{ACKNOWLEDGEMENTS}

This study was financially supported in part by a Grant-in-Aid (15580146) from the Ministry of Education, Science, Sports and Culture of Japan. We thank Drs J. Kajihara and T. Tokimatsu for kind help with determining amino acid sequences. We thank Drs Kazufumi Yazaki and Toshiaki Umezawa for technical assistance in molecular biology work. We thank Ms Mukumoto for kind support in preparing antibody.

\section{REFERENCES}

Aebi, H. E. (1983). Catalase. In Methods of Enzymatic Analysis, 3rd edn, pp. 273-285. Edited by H. U. Bergmeyer. Weinheim: Verlag Chemie.

Amor, C., Dominguez, A. I., de Lucas, J. R. \& Laborda, F. (2000). The catabolite inactivation of Aspergillus nidulans, isocitrate lyase occurs by specific autophagy of peroxisomes. Arch Microbiol 174, 59-66.

Atomi, H., Ueda, M., Hikida, M., Hishida, T., Teranishi, Y. \& Tanaka, A. (1990). Peroxisomal isocitrate lyase of the $n$-alkaneassimilating yeast Candida tropicalis: gene analysis and characterization. J Biochem 107, 262-266.

Bradford, M. M. (1976). A rapid and sensitive method for the quantitation of microgram quantities of protein utilizing the principle of protein-dye binding. Anal Biochem 72, 248-254.

Campbell, J. J. R., Smith, R. A. \& Eagles, B. A. (1953). A deviation from the conventional tricarboxylic acid cycle in Pseudomonas aeruginosa. Biochim Biophys Acta 11, 594.

Chaure, P. T., Casselton, L. A. \& Connerton, I. F. (1997). Molecular analysis of the isocitrate lyase gene $(a c u-7)$ of the mushroom Coprinus cinereus. Gene 184, 185-187.

Chaves, R. S., Herrero, P., Ordiz, I., del Brio, M. A. \& Moreno, F. (1997). Isocitrate lyase localisation in Saccharomyces cerevisiae cells. Gene 198, 165-169.

De Lucas, J. R., Valenciano, S., Laborda, F. \& Turner, G. (1994). Glucose-induced inactivation of isocitrate lyase in Aspergillus nidulans. Arch Microbiol 162, 409-413.

Dijken, J. P. V., Beenhuis, M., Vermeulen, C. A. \& Harder, W. (1975). Cytochemical localization of catalase activity in methanol-grown Hansenula polymorpha. Arch Microbiol 105, 261-267.

Dixon, G. H. \& Kornberg, H. L. (1959). Assay method for key enzymes of the glyoxylate cycle. Biochem J 72, 3p.

Dutton, M. V. \& Evans, C. S. (1996). Oxalate production by fungi: its role in pathogenicity and ecology in the soil environment. Can J Microbiol 42, 881-895.

Fahimi, H. D. \& Baumgart, E. (1999). Current cytochemical techniques for the investigation of peroxisomes, a review. J Histochem Cytochem 47, 1219-1232. 
Fernández, E., Moreno, F. \& Rodicio, R. (1992). The $I C L 1$ gene from Saccharomyces cerevisiae. Eur J Biochem 204, 983-990.

Flores, C.-L., Rodríguez, C., Petit, T. \& Gancedo, C. (2000). Carbohydrate and energy-yielding metabolism in non-conventional yeasts. FEMS Microbiol Rev 24, 507-529.

Gainey, L. D. S., Connerton, I. F., Lewis, E. H., Turner, G. \& Balance, D. J. (1992). Characterization of the glyoxysomal isocitrate lyase genes of Aspergillus nidulans (acuD) and Neurospora crassa (acu-3). Curr Genet 21, 43-47.

Heather, M. S.-L. \& Fairhurst, V. (1998). Isolation of mutants deficient in acetyl-CoA synthetase and a possible regulator of acetate induction in Aspergillus niger. Microbiology 144, 1895-1900.

Herrero, P., Fernández, R. \& Moreno, F. (1985). Differential sensitivities to glucose and galactose repression of gluconeogenic and respiratory enzymes. Arch Microbiol 143, 216-219.

Kionka, C. \& Kunau, W. (1985). Inducible $\beta$-oxidation pathway in Neurospora crassa. J Bacteriol 161, 153-157.

Kornberg, H. L. (1966). The role and control of the glyoxylate cycle in Escherichia coli. Biochem J 99, 1-11.

Kornberg, H. L. \& Krebs, H. A. (1957). Synthesis of cell constituents from $\mathrm{C}_{2}$-units by a modified tricarboxylic acid cycle. Nature 179, 988-991.

Kornberg, H. L. \& Madsen, N. B. (1957). Synthesis of C-dicarboxylic acids from acetate by a glyoxylate bypass of the tricarboxylic acid cycle. Biochim Biophys Acta 24, 651-653.

Labrou, N. E. \& Clonis, Y. D. (1997). L-Malate dehydrogenase from Pseudomonas stutzeri: purification and characterization. Arch Biochem Biophys 337, 103-114.

Laemmli, U. K. (1970). Cleavage of structural proteins during the assembly of the head of bacteriophage T4. Nature 227 , 680-685.

Lee, J. G., Cho, S. P., Lee, H. S., Lee, C. H., Bae, K. S. \& Maeng, P. J. (2000). Identification of a cryptic N-terminal signal in Saccharomyces cerevisiae peroxisomal citrate synthase that functions in both peroxisomal and mitochondrial targeting. J Biochem 128, 1059-1072.

Lenz, H., Wunderwald, P. \& Eggerer, H. (1976). Partial purification and some properties of oxaloacetase from Aspergillus niger. Eur J Biochem 63, 225-236.

López, M. L., Redruello, B., Valdes, E., Moreno, F., Heinisch, J. J. \& Rodicio, R. (2004). Isocitrate lyase of the yeast Kluyveromyces lactis is subject to glucose repression but not to catabolite inactivation. Curr Genet 44, 305-316.

López-Boado, Y. S., Herrero, P., Ferández, T., Ferández, R. \& Moreno, F. (1988). Glucose-stimulated phosphorylation of yeast isocitrate lyase in vivo. J Gen Microbiol 134, 2499-2505.

Maeting, I., Scimdit, G., Sahm, H., Revuelta, J. L., Stierhof, Y. D. \& Stahmann, K. P. (1999). Isocitrate lyase of Ashbya gossypii transcriptional regulation and peroxisomal localization. FEBS Lett 444, 15-21.

Moore, D. \& Ewaze, J. O. (1976). Activities of some enzymes involved in metabolism of carbohydrate during sporophore development in Coprinus cinereus. J Gen Microbiol 97, 313-322.

Munir, E., Yoon, J. J., Tokimatsu, T., Hattori, T. \& Shimada, M. (2001a). New role for glyoxylate cycle enzymes in wood-rotting basidiomycetes in relation to biosynthesis of oxalic acid. J Wood Sci 47, 368-373.

Munir, E., Yoon, J. J., Tokimatsu, T., Hattori, T. \& Shimada, M. (2001b). A physiological role for oxalic acid biosynthesis in the wood-rotting basidiomycete Fomitopsis palustris. Proc Natl Acad Sci U S A 98, 11126-11130.
Munir, E., Hattori, T. \& Shimada, M. (2002). Purification and characterization of isocitrate lyase from the wood-destroying basidiomycete Fomitopsis palustris grown on glucose. Arch Biochem Biophys 399, 225-231.

Ono, K., Kondo, M., Osafune, T., Miyatake, K., Inui, H., Kitaoka, S., Nishimura, M. \& Nakano, Y. (2003). Presence of glyoxylate cycle enzymes in the mitochondria of Euglena gracilis. J Eukaryot Microbiol 50, 92-96.

Ordiz, I., Herrero, P., Rodicio, R. \& Moreno, F. (1996). Glucoseinduced inactivation of isocitrate lyase in Saccharomyces cerevisiae is mediated by the cAMP-dependent protein kinase catalytic subunits Tpk1 and Tpk2. FEBS Lett 385, 43-46.

O'sullivan, J. \& Casselton, P. J. (1973). The subcellular localization of glyoxylate cycle enzymes in Coprinus lagopus. J Gen Microbiol 75, 333-337.

Osumi, M., Katazawa, H. \& Sato, S. (1978). Microbody-associated DNA in Candida tropicalis pk223 cells. FEBS Lett 90, 309-312.

Petrova, V. Y., Rasheva, T. V. \& Kujumdzieva, A. V. (2002). Catalase enzyme in mitochondria of Saccharomyces cerevisiae. Electron J Biotechnol 5, 29-41.

Ruijter, G. J. G., Van de Vondervoort, P. J. I. \& Visser, J. (1999). Oxalic acid production by Aspergillus niger: an oxalate-nonproducing mutant produces citric acid at $\mathrm{pH} 5$ and in the presence of manganese. Microbiology 145, 2569-2576.

Sambrook, J., Fritsch, E. F. \& Maniatis, T. (1989). Molecular Cloning: a Laboratory Manual, 2nd edn. Cold Spring Harbor, NY: Cold Spring Harbor Laboratory.

Schöler, A. \& Schüller, H. J. (1993). Structure and regulation of the isocitrate lyase gene ICL1 from the yeast Saccharomyces cerevisiae. Curr Genet 23, 375-381.

Schüller, H. J. (2003). Transcriptional control of nonfermentative metabolism in the yeast Saccharomyces cerevisiae. Curr Genet 43, 139-160.

Shimada, M., Akamatsu, Y., Tokimatsu, T., Mii, K. \& Hattori, T. (1997). Possible biochemical roles of oxalic acid as a low molecular weight compound involved in brown-rot and white-rot wood decays. J Biotechnol 53, 103-113.

Spurr, A. R. (1969). A low viscosity epoxy resin embedding medium for electron microscopy. J Ultrastruct Res 26, 31-43.

Steffan, J. S. \& McAlister-Henn, L. (1992). Isolation and characterization of the yeast gene encoding the MDH3 isozyme of malate dehydrogenase. J Biol Chem 267, 24708-24715.

Subramani, S. (1993). Protein import into peroxisomes and biogenesis of the organelle. Annu Rev Cell Biol 9, 445-478.

Tanaka, A. \& Ueda, M. (1993). Assimilation of alkanes by yeasts - functions and biogenesis of peroxisomes. Mycol Res 97, 1025-1044.

Taylor, K. M., Kaplan, C. P., Gao, X. \& Baker, A. (1996). Localization and targeting of isocitrate lyases in Saccharomyces cerevisiae. Biochem J 319, 255-262.

Thompson, J. D., Higgins, D. G. \& Gibson, T. J. (1994). CLUSTAL W: improving the sensitivity of progressive multiple sequence alignment through sequence weighting, position-specific gap penalties and weight matrix choice. Nucleic Acids Res 22, 4673-4680.

Titorenko, V. I., Smith, J. J., Szilard, R. K. \& Rachubinski, R. A. (1998). Pex20p of the yeast Yarrowia lipolytica is required for the oligomerization of thiolase in the cytosol and for its targeting to the peroxisome. J Cell Biol 142, 403-420.

Valenciano, S., De Lucas, J. R., Pedregosa, A., Monistrol, I. F. \& Laborda, F. (1996). Induction of $\beta$-oxidation enzymes and 
microbody proliferation in Aspergillus nidulans. Arch Microbiol 166, 336-341.

Valenciano, S., De Lucas, J. R., Van der Klei, I. \& Veenhuis, M. \& Laborda, F. (1998). Characterization of Aspergillus nidulans peroxisomes by immunoelectron microscopy. Arch Microbiol 170, 370-376.
Vanni, P., Giachetti, E., Pinzauti, G. \& McFadden, B. A. (1990). Comparative structure, function and regulation of isocitrate lyase, an important assimilatory enzyme. Comput Biochem Physiol B95, 431-458.

Wong, D. T. O. \& Aji, S. J. (1956). Conversion of acetate and glyoxylate to malate. J Am Chem Soc 78, 3230-3231. 